\title{
Taman Budaya Raja Ali HaJi dengan PENDEKatan KEARIFAN LOKAL DI TANJUNGPINANG
}

\author{
Niken Arimbi, Rachmadi Nugroho, Suparno \\ Program Studi Arsitektur Fakultas Teknik Universitas Sebelas Maret Surakarta \\ Email: nikenarimbi@student.uns.ac.id
}

\begin{abstract}
Malayan culture given a lot of culture heritage, even it is an object or not. Pass through culture creation, the point of view of a region could be known. The downfall of Majapahit kingdom caused the development of islamic kingdom in the malayan territory, ingclude in the Kesultanan Riau Lingga. The efforts that have been done by the local goverment is pary seriousness to do conservation of local culture. But all of these efforts has not given any real result yet. To embed the identity of the culture city, the goverment of Tanjungpinang announced officially a zone that is called Taman Budaya Raja Ali Haji is based on the discerment aspect of local malayan culture that has been formed that origin citizen or new comers indirectly affects by the usual and culture of Malayan. Taman Budaya Raja Ali Haji came out from thoughts about an effort in Tanjungpinang. The discernment of Malayan local culture became the strength of culture that the origin citizen and new comers have who lived at Malayan zone.
\end{abstract}

Keywords: Taman Budaya Raja Ali Haji, malayan culture, local wisdom

\section{PENDAHULUAN}

Budaya melayu menghasilkan berbagai karya budaya peninggalan masa lalu yang berwujud benda maupun non-benda. Melalui karya budaya, perspektif suatu daerah tetentu dapat diketahui. Keruntuhan Majapahit menyebabkan perkembangan kerajaan-kerajaan islam di daerah melayu, yaitu Kesultanan Riau Lingga.

Kesultanan Riau Lingga banyak meninggalkan warisan budaya melayu serta situs-situs sejarah melayu di beberapa cagar budaya propinsi Kepulauan Riau yang menyimpan ketakjuban luar biasa pada zaman tersebut.

Upaya yang telah dilakukan oleh pemerintah daerah adalah bagian dari keseriusan guna melakukan pelestarian budaya lokal, tetapi segala upaya tersebut belum menghasilkan kerja nyata. Masih ditemukan berbagai kenyataan tentang tindakan penelantaran atau membiarkan beberapa situs-situs sejarah Kesultanan Riau Lingga. Untuk melekatkan identitas kota budaya tersebut, pemerintah Kota Tanjungpinang meresmikan suatu kawasan yang disebut taman budaya Raja Ali Haji di kelurahan Senggarang, kota Tanjungpinang.
Taman budaya Raja Ali Haji dalam proses perkembangan yang stagnan, belum memberikan kabar positif dalam peran ketahanan budaya melayu di Kepulauan Riau. Keadaan taman budaya Raja Ali Haji , belum menunjukkan wadah secara arsitektur mampu menampung kegiatan seni budaya melayu Riau serta tampilan yang mampu menguatkan karakter kearifan lokal Kepualaun Riau.

Desain arsitektur perencanaan taman budaya Raja Ali Haji, didasarkan pada penekanan aspek kearifan lokal budaya melayu, yang sudah menjadi bentuk tatanan masyarakat asli maupun pedatang secara tidak langsung terbawa oleh kebiasaan dan kebudayaan melayu tersebut. Kebiasaan tersebut mempengaruhibahasa, bertutur kata serta bersikap. Keterbukaan yang dimiliki oleh sifat orang melayu menyebabkan budaya melayu mudah diterima oleh masyarakat pendatang. Kearifan budaya melayu menjadi kekuatan budaya yang dimiliki oleh masyarakat asli maupun pendatang yang berpijak di tanah melayu.

\section{METODE}

Taman budaya Raja Ali Haji bermula dari pemikiran tentag upaya, dalam menciptakan 
suatu wadah untuk mewadahi kegiatan yang berhubungan dengan seni budaya melayu di Tanjungpinang. Straegi desain yang digunakan yaitu pendekatan kearifan lokal dalam arsitekur, yang disadur dari berbagai sumber para ahli. Serta diselaraskan dengan kearifan lokal melayu Riau yang dinukil dari Butang Emas Warisan Budaya Melayu Kepualauan Riau, sebagai manifestasi prinsip yang mampu diimplementasikan ke dalam Taman Budaya Raja Ali Haji.

\subsection{Nilai Kearifan Lokal intangible \\ 2.1.1 Pengetahuan Lokal}

Masyarakat yang berada di kepulauan, identik dengan pengetahuan lokal yang berkaitan erat dengan lingkungan binaannya.

\subsubsection{Nilai Lokal}

Nilai lokal merupakan bagian dari aturanaturan yang telah disepakati oleh seluuh anggota kelompok atau masyrakat.

\subsubsection{Keterampilan Lokal}

Kemampuan bertahan hidup dari setiap masyarakat, dapat dipenuhi jika masyarakat tersebut memiliki keterampilan lokal.

\subsubsection{Sumber Daya Lokal}

Sumber daya lokal yaitu sumber daya yang tidak terbarui dan yang dapat diperbarui.

\subsubsection{Mekanisme Pengambilan Keputusan Lokal}

Menurut ahli adat dan budaya, setiap masyarakat memiliki pemerintahan lokal sendiri atau disebut pemerintahan kesukuan.

\subsection{Nilai Kearifan Lokal tangible}

\subsubsection{Tekstual}

Beberapa jenis kearifan lokal seperti sistem nilai, tata cara, ketentuan khusus yang dituangkan ke dalam bentuk catatan tertulis seperti yang ditemui dalam kitab. Masyarakat melayu Rau identik dengan tradisi yang islami dengan berpayugkan kepada kitabullah

\subsubsection{Bangunan/Arsitektural}

Banyak bangunan-bangunan tradisional, yang merupakan cerminan dari bentuk kearifan lokal. Seperti bangunan rumah masyarakat melayu Kepulauan Riau.

\subsubsection{Benda Cagar}

Beda dan cagar budaya merupakan salah satu betuk kearifan lokal, contohnya, keris.

\subsubsection{Kondisi Lingkungan}

Sebagian wilaya Tanjungpinang merupakan daerah rendah, kawasan rawa bakau dan sebagian yang lain merupakan perbukitan rendah sehvngga lahan kota sangat bervariasi dan berkontur.

\section{ANALISIS}

Pada sub bab analisis akan dibahas tentang analisis perencanaan an perancangan Taman Budaya Raja Ali Haji, berupa pendekatan, peruangan, lokasi tapak, dan struktur.

\subsection{Analisis Peruangan}

\subsubsection{Tujuan}

Kebutuhan ruang

\subsubsection{Dasar pertimbangan}

Pelaku kegiatan, jenis kegiatan, dan pola kegiatan.

\subsubsection{Proses analisis}

Tabel 1. Analisis Kebutuhan Ruang

\begin{tabular}{|l|l|}
\hline KELOMPOK & KEBUTUHAN \\
KEGIATAN & RUANG \\
\hline Kegiatan Informasi & $\begin{array}{l}\text { R. Informasi, Ruang } \\
\text { Keamanan }\end{array}$ \\
\hline $\begin{array}{l}\text { Kegiatan } \\
\text { Pertunjukan }\end{array}$ & $\begin{array}{l}\text { R. Teater terbuka, } \\
\text { R.Teater tertutup }\end{array}$ \\
\hline Kegiatan Pameran & $\begin{array}{l}\text { R. Pameran tetap, R. } \\
\text { Pameran temporer }\end{array}$ \\
\hline Kegiatan Seniman & $\begin{array}{l}\text { Bengkel seni tari, } \\
\text { musik, teter dan } \\
\text { rupa. }\end{array}$ \\
\hline $\begin{array}{l}\text { Kegiatan } \\
\text { Penunjang }\end{array}$ & $\begin{array}{l}\text { Kantin, Dapur, } \\
\text { Penginapan. }\end{array}$ \\
\hline Kegiatan Pengelola & $\begin{array}{l}\text { R. Kepala, R. } \\
\text { Administrasi, R. } \\
\text { Tamu, R. Karyawan, } \\
\text { R. Rapat }\end{array}$ \\
\hline Kegiatan Servis & $\begin{array}{l}\text { R. Pompa, R. Genset, } \\
\text { R. AHU, R. Panel } \\
\text { Listrik }\end{array}$ \\
\hline
\end{tabular}

Pada Tabel 1. terlihat kebutuhan peruangan yang dibutuhkan dalam pemenuhan wadah Taman Budaya Raja Ali Haji.

\subsection{Analisis Luasan Ruang \\ 3.2.1 Tujuan \\ Luasan ruang \\ 3.2.2 Dasar pertimbangan}


Jenis kegiatan yang diwadahi, jumlah pelaku, peralatan pendukung yang digunakan dan kenyamanan sirkulasi.

\subsubsection{Proses analisis}

Perhitungan besaran ruang dalam taman budaya yang direncanakan sebagai berikut:

1. Kelompok kegiatan pendukung dan informasi $= \pm 2419 \mathrm{~m}^{2}$

2. Kelompok kegiatan pertunjukan $= \pm 2332$ $\mathrm{m}^{2}$

3. Kelompok kegiatan pameran $= \pm 1053 \mathrm{~m}^{2}$

4. Kelompok kegiatan bengkel seni $= \pm 1082$ $\mathrm{m}^{2}$

5. Kelompok kegiatan penunjang $= \pm 332 \mathrm{~m}^{2}$

Total luas kebutuhan ruang $= \pm 7223 \mathrm{~m}^{2}$.

\subsection{Analisis Lokasi}

\subsubsection{Tujuan}

Lokasi tapak

\subsubsection{Dasar pertimbangan}

Tapak berpotenasi bagi terciptanya nuansa kearifan lokalpada bangunan dan luasan tapak dapat menampung seluruh kebutuhan ruang yang direncanakan.

\subsubsection{Proses analisis}

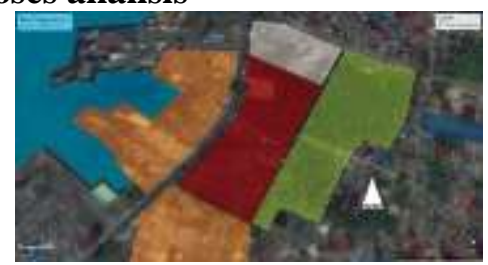

Gambar 1. Lokasi Tapak

Lokasi tapak Taman Budaya Raja Ali Haji, Kota Tanjungpinang

(lihat Gambar 1).

\subsection{Analisis Pencapaian \\ 3.4.1 Tujuan}

Main entrance dan side entrance

\subsubsection{Dasar pertimbangan}

Kemudahan akses, sirkulasi tapak yang aksesibel, arus kendaraan dan potensi jalan, tngkat keamanan.

\subsubsection{Proses analisis}

Letak main entrance berada di sisi Jalan Usman Harun, karena lebih mudah dijangkau dari berbagai sisi jalan serta perempatan jalan sekitar tapak. Side entrance ditentukan berada disekeliling samping atau sejajar dengan main entrance dengan penanda yang terlihat jelas antara kedua jalan. (lihat Gambar 2)

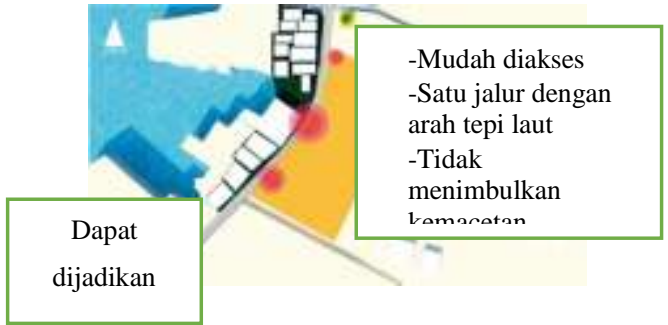

\subsection{Analisis Klimatologis dan Kebisingan}

\subsubsection{Tujuan}

Analisis sinar matahari dan arah aliran udara dibutuhkan sebagai dasar pertimbangan dalam tata ruang, bukaan, serta pemilihan material bangunan.

Analisis tingkat kebisingan bertujuan untuk dapat merespon pemintakan ruang dan peletakkan vegetasi.

\subsection{Analisis Pemintakatan}

\subsubsection{Tujuan}

Zona ruang

\subsubsection{Dasar pertimbangan}

Analisis peruangan, analisis pengolahan tapak, analisis struktur.

\subsubsection{Proses analisis}

Pertimbangan mintakat terkait kedekatan hubungan ruang didasarkan pada analisa peruangan yang sudah dilakukan. (lihat Gambar 3)

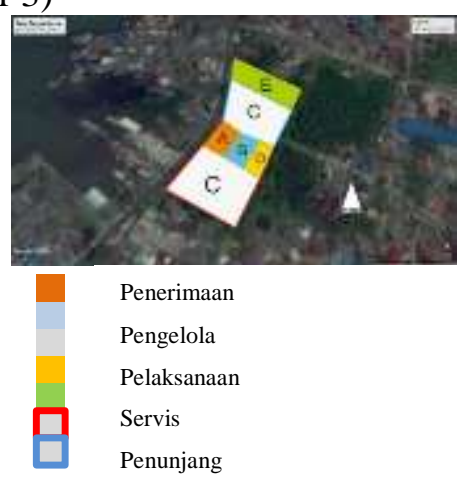

Gambar 3. Analisis Pemintakan

\subsection{Analisis Bentuk dan Ruang Luar}

\section{Bangunan}

3.7.1 Analisis Bentuk Bangunan

\subsubsection{Tujuan}

Bentuk bangunan

\subsubsection{Dasar pertimbangan}

Kearifan lokal

\subsubsection{Proses analisis}

Bentuk-bentuk dasar banguan Taman Budaya Raja Ali Haji merupakan bentuk yang dinamis dn mengacu pada karakter rumah adat melayu Riau, dengan sedikit gubahan pada 
bentuk dan mengikuti perkembangan zaman namun tetap mengalami kolaborasi dengan karakter tradisional Melayu.

Bentuk rumah melayu terbagi menjadi dua, yaitu (1) bentuk persegi panjang dengan bubungan panjang (rumah bubungan melayu atau rumah belah bubung) yang disebut rumah melintang atau bubungan melayu, dan (2) bentuk segi empat dengan bubungan berbentuk limas dan disebut rumah limas.

Rumah melayu terdiri dari tiga unsur utama yaitu tiang (pondasi), dinding dan bumbung. Kekuatan dan ketahanan sebuah rumah tergantung dari bahan-bahan binaan. Susunan rumah melayu terdiri dari rasuk, gelegar, tongkat, tangga, bendul, lantai, jenang, sentur, tutup tiang, alang, kasau, gulung-gulung, tulang bubung, tunjuk langit, dinding, pintu, tingkap, lubang angin, loteng, tebang layar, atap dan bubung.
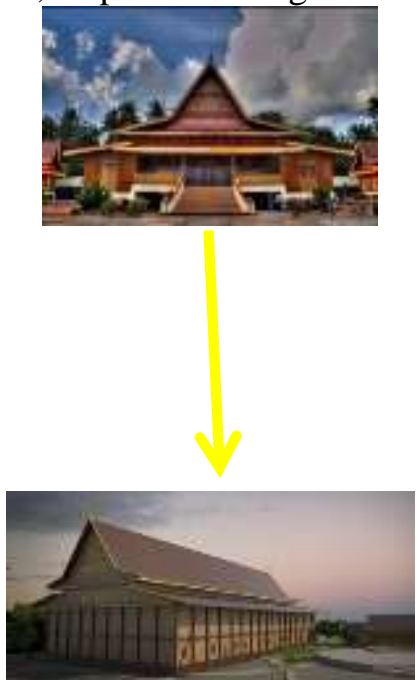

Gambar 4. Analisis Bentuk Bangunan

Gubahan massa yang dibangun mengadopsi karateristik kearifan lokal melayu Riau dari segi pemilihan material, ornamentasi hingga penyelesaian keseluruhan bangunan.

\subsubsection{Analisis Ruang Luar Bangunan}

\subsubsection{Tujuan}

Tampilan bangunan

\subsubsection{Dasar pertimbangan}

Kearifan lokal

\subsubsection{Proses analisis}

Ruang luar bangunan Taman Budaya

Raja Ali Haji, yang direncanakan menggunakan material yang juga diadopsi oleh bangunan -bangunan lokal rumah adat melayu Riau. Kayu dan papan menjadi plhan utama, karena mudah ditemukan serta menjadi bahan dasar rumah meayu, sedangkan penggunaan beton dan baja adalah penunjang struktur yang ada.

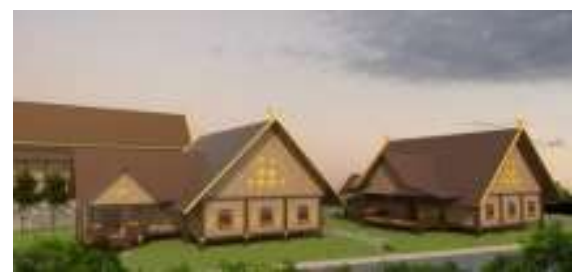

Gambar 5. Analisis Penggunaan Material

Ornamentasi yang diterapkan pada desain rumah tradisional maupun modern melayu Riau sebagai tolak ukur desain. Desain ornamen yang non-figuratif tetap bersinggungan dengan unsur islami karena islam melarang menggunaan karakter sesosok manusia pada bentuk ornamen. Maka pada bangunan Taman Buday Raja Ali Hai menggunakan bentuk bunga dan hewan.
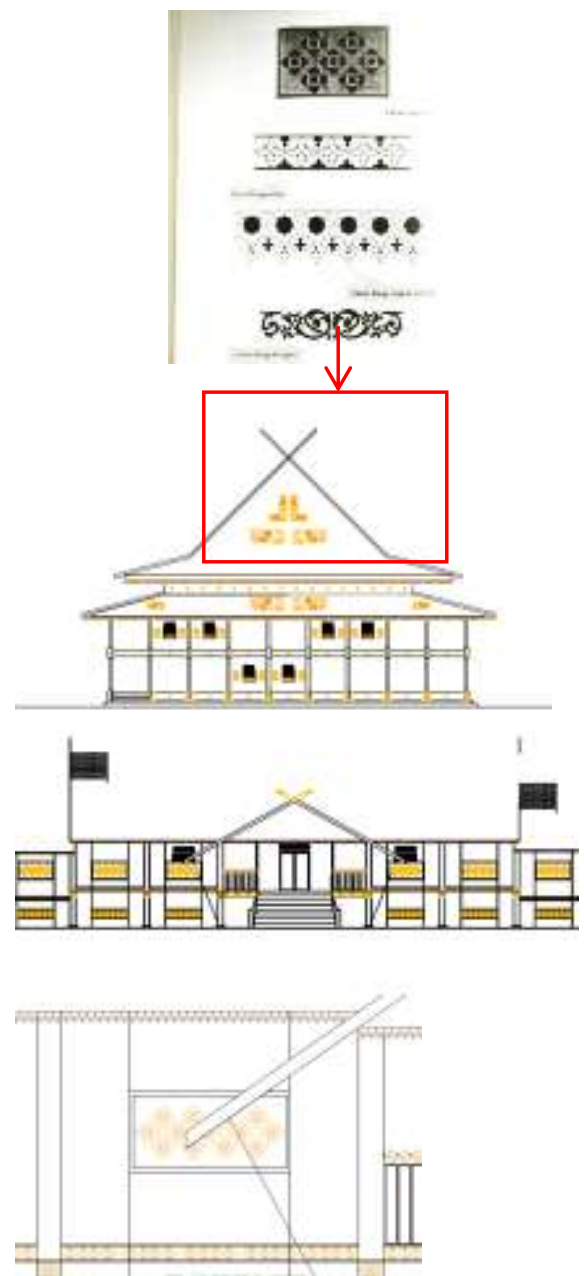

Gambar 6. Tampilan Bangunan

\subsection{Analisis Struktur}

3.8.1 Struktur Bawah

3.8.1.1 Tujuan 
Pondasi bangunan.

\subsubsection{Dasar pertimbangan}

Struktur bangunan bertingkat rendah dan kondisi tanah pada bangunan.

\subsubsection{Proses analisis}

Struktur fondasi yang digunakan pada Taman Budaya Raja Ali Haji adalah fondasi tiang pancang yakni berbentuk panjang dan langsing yang menyalurkan beban ke tanah yang lebih dalam.

\subsubsection{Struktur Tengah \\ 3.8.2.1 Tujuan}

Struktur badan bangunan.

\subsubsection{Dasar pertimbangan}

Memiliki fleksibilitas tinggi, ringan dan ekonomis, dan kemampuan menahan gayagaya lateral dan kekakuan.

\subsubsection{Proses analisis}

Penggunaan rangka kayu disesuaikan dengan karakter rumah melayu yakni dengan menggunakan fasad dinding papan (kayu yang disusun secara horisontal.

Rumah melayu semula memiliki tiang atau kolom yang ditanam ditanah, namun pada masa kini Rumah Bubung Panjang sudah memakai alas pada kaki tiang (kolom) yang disebut lapik tiang atau alam tiang yang dibuat dari kayu atau bahan yang keras.

\subsubsection{Struktur Atas \\ 3.8.3.1 Tujuan}

Struktur atap.

\subsubsection{Dasar pertimbangan}

Kondisi bangunan eksisting.

\subsubsection{Proses analisis}

Struktur atap yang digunakan pada Taman Budaya Raja Ali Haji yakni struktur kayu dan struktur baja ringan. Sedangkan material lokal penutup atap adalah asbes, genteng alumunium dan beberapa kombinasi dari material alam seperti anyaman rumbia.

\section{KESIMPULAN}

Konsep rancangan Taman Budaya Raja Ali Haji mengacu pada konsep pendekatan Kearifan Lokal. Dari hasil analisa serta hasil korelasi dari beberapa data di atas, maka diperoleh hasil berupa rancangan Taman Budaya Raja Ali Haji di Tanjungpinang sebagai berikut:

\subsection{Bentuk}

Bentuk rumah Melayu terbagi menjadi dua, yaitu (1) bentuk persegi panjang dengan bubungan panjang (rumah bubung Melayu

atau rumah belah bubung) yang disebut rumah melintang atau disebut juga bubungan Melayu, dan (2) bentuk segi empat dengan bubungan berbentuk limas dan disebut rumah limas. Rumah Melayu terdiri dari tiga unsur utama yaitu tiang (pondasi), dinding dan bumbung.

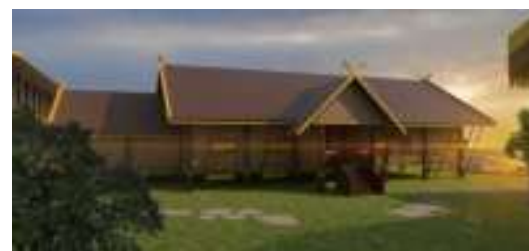

Gambar 7. Perspektif Bangunan

\subsection{Warna dan Material}

Warna diperoleh dari bahan bangunan asli maupun diolah (di cat/kapur). Bahan-bahan utama yang memunculkan karakter warna pada bangunan taman budaya adalah kayu, asbes, alumunium, rumbia dan seng. Sedangkan warna dan material pada taman menggunakan bahan-bahan alam seperti batu, tanah liat, bata dan tanah.

\subsection{Elemen Arsitektural}

Penerapan beberapa ornamen pada elemen arsitektural di Taman Budaya Raja Ali Haji(lihat Gambar 8).

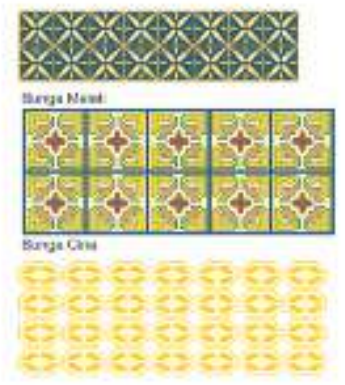

Gambar 8. Ornamentasi Rumah Melayu

\subsection{Struktur}

Penerapan struktur pada bangunan menggunakan struktur atap kuda-kuda yang disesuaikan dengan atap rumah bubungan panjang. (lihat Gambar 9).

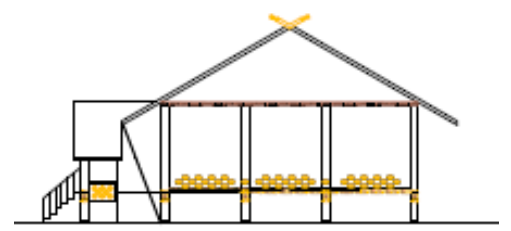

Gambar 9. Tampak Samping

Lokasi : Jalan Usman Harun

Luas Lahan $\quad: 12.500 \mathrm{~m}^{2}$ 
Luas Bangunan : $7300 \mathrm{~m}^{2}$

Kegiatan : Pertunjukan, Pameran,

Taman.

\section{REFERENSI}

Suseno, Tusiran, Drs. Amiruddin, dan Teja AlHabd.2006."Butang Emas" Warisan Budaya
Melayu, Tanjungpinang: Yayasan Pusaka Bunda

Jee Yuan, Lee.1987.The Malay House Rediscovering Malaysia's Indigenous Shelter System. Kuala Lumpur: Insitut Masyarakat 